\title{
Single layer centrifugation-selected boar spermatozoa are capable of fertilization in vitro
}

\author{
Ylva Cecilia Björnsdotter Sjunnesson ${ }^{1,2^{*}}$, Jane Margaret Morrell ${ }^{1,2}$ and Raquel González ${ }^{1}$
}

\begin{abstract}
Background: Good quality spermatozoa are important to achieve fertilization, viable embryos and offspring. Single Layer Centrifugation (SLC) through a colloid (Androcoll-P) selects good quality spermatozoa. However, it has not been established previously whether porcine spermatozoa selected by this method maintain their fertility.

Methods: The semen was prepared either by SLC or by standard centrifugation (control) and used for in vitro fertilization (IVF) at oocyte:spermatozoa ratios of 1:50; 1:100 and 1:300 (or $4 \times 10^{3}, 8 \times 10^{3}$ and $24 \times 10^{3}$ spermatozoa/ml) to evaluate their subsequent ability to generate blastocysts. In addition, sperm motility was assessed by computer assisted sperm motility analysis.

Results: Total and progressive motility were significantly higher in sperm samples prepared by SLC compared to uncentrifuged samples. Sperm binding ability, polyspermy, cleavage and blastocyst rates were affected by the oocyte:sperm ratio, but not by sperm treatment.

Conclusion: The use of SLC does not adversely affect the in vitro fertilizing and embryo-generating ability of the selected spermatozoa compared to their unselected counterparts, but further modifications in the IVF conditions would be needed to improve the monospermy in IVF systems. Since SLC did not appear to have a negative effect on sperm fertilizing ability, and may in fact select for spermatozoa with a greater potential for fertilization, an in vivo trial to determine the usefulness of this sperm preparation technique prior to artificial insemination is warranted.
\end{abstract}

Keywords: IVF, Pig, Semen, Sperm selection

\section{Background}

During natural mating, physiological selection of suitable spermatozoa takes place in the female reproductive tract [1]. The availability of good quality spermatozoa is important to achieve successful fertilization, viable embryos and healthy offspring. Therefore, in an attempt to select the best spermatozoa in an ejaculate, several in vitro strategies have been developed for processing spermatozoa for their use in assisted reproduction [2,3]. Among these methods, colloid centrifugation separates spermatozoa from seminal plasma and selects spermatozoa on the basis of sperm motility, morphology, viability and chromatin integrity [4].

Single Layer Centrifugation (SLC) has arisen as an alternative method to other colloid preparations, providing

\footnotetext{
* Correspondence: ylva.sjunnesson@slu.se

'Department of Clinical Sciences, Division of Reproduction, Swedish University of Agricultural Sciences, P.O. Box 7054, Uppsala, SE 750 07, Sweden

${ }^{2}$ Centre for Reproductive Biology in Uppsala, Swedish University of Agricultural Sciences, P.O. Box 7054, Uppsala, SE 750 07, Sweden
}

several technical advantages, such as ready-to-use speciesspecific formulations; homogeneity between batches of colloid; and the possibility of scaling up to process whole/ large ejaculates (as it is the case of the boar and the stallion), which may facilitate its application for commercial semen preparation purposes $[4,5]$.

The fertilizing ability of bull spermatozoa selected by SLC has been demonstrated using in vitro fertilization (IVF) [6] and the functionality of SLC-treated stallion sperm has been proven after artificial insemination, showing promising results even with low quality semen [7].

SLC through a species-specific colloid (Androcoll-P), has also been developed for use with boar semen, enabling spermatozoa with good motility [8] and morphology [9] to be selected, while maintaining sperm plasma membrane ultrastructure and integrity [10,11]. However, the boar spermadhesins PSP-I and PSP-II (porcine seminal plasma proteins 1 and II, respectively), some of the proteins present in the seminal plasma, are removed from the sperm surface

\section{Biomed Central}

(c) 2013 Sjunnesson et al.; licensee BioMed Central Ltd. This is an Open Access article distributed under the terms of the Creative Commons Attribution License (http://creativecommons.org/licenses/by/2.0), which permits unrestricted use, distribution, and reproduction in any medium, provided the original work is properly cited. 
by SLC [10]. They are involved in maintaining or inhibiting sperm motility, membrane integrity, mitochondrial activity, zona pellucida binding and penetration and, ultimately, affect the ability of the spermatozoa to fertilize [12-14]. In addition, SLC may remove cholesterol from the sperm plasma membrane during the process of colloid centrifugation, although the integrity of the sperm membrane seemed not to be altered [10]. It is unknown if these, and possibly other, inadvertent, alterations of boar spermatozoa may hamper the fertilizing ability of SLC-selected spermatozoa and, therefore, it is essential to examine whether the fertilizing ability of SLC-selected boar sperm is affected before attempting artificial insemination.

Thus, the aim of this study was to evaluate the fertilizing ability of boar sperm selected by SLC and the production of embryos using in vitro fertilization and embryo culture. The main findings of the present study were that sperm selected by SLC were able to fertilize oocytes and the proportion of embryos developing to blastocyst was similar to the embryo production in their unselected counterparts.

\section{Methods}

All reagents were purchased from Sigma-Aldrich, Stockholm, Sweden unless otherwise stated.

\section{Semen collection}

All experiments were approved by the Ethical Committee for Experimentation with Animals, Uppsala, Sweden. The same boar (Swedish Landrace of proven fertility) was used throughout the experiment, housed and fed according to Swedish husbandry standards [15]. Semen was collected using the gloved hand technique, with a filter to remove the bulbo-urethral gland secretion. The sperm-rich fraction was extended after collection with Beltsville Thawing Solution (BTS) containing $0.2 \mathrm{mg} / \mathrm{ml}$ gentamicin sulphate (005974-ZG863, IMV technologies, L’Aigle, France) 1:1 (v/v) at $35^{\circ} \mathrm{C}$ and stored for $1-2$ days at $16^{\circ} \mathrm{C}$.

\section{Oocyte collection and in vitro maturation}

Ovaries from gilts were obtained at an abattoir, placed in $0.9 \%(\mathrm{w} / \mathrm{v}) \mathrm{NaCl}$ solution at $30-35^{\circ} \mathrm{C}$ and transported to the laboratory within $3-4 \mathrm{~h}$ of collection. Follicles with a diameter of 3-8 mm were aspirated using an 18gauge needle and a $5 \mathrm{ml}$ syringe. Aspiration medium consisted of HEPES-buffered TCM 199 (M 2520) with $26 \mathrm{mM} \mathrm{NaHCO}_{3}$ (S 5761), 1 mM L-glutamine (G 8540), $0.5 \mathrm{mg} / \mathrm{ml}$ polyvinyl alcohol (P 8136), $50 \mu \mathrm{g} / \mathrm{ml}$ gentamicin (G 1264) and $20 \mathrm{U} / \mathrm{ml}$ heparin (H 3149). The oocytes were retrieved in the same medium without heparin using a stereo microscope. Oocytes with even, dark cytoplasm and more than two compact layers of cumulus cells were selected, washed twice in in vitro maturation medium (IVM) and placed in groups of 4060 in a final volume of $500 \mu \mathrm{l}$ of IVM. Oocytes were cultured at $38.5^{\circ} \mathrm{C}$ under $5 \% \mathrm{CO}_{2}$ in air and maximum humidity for $46 \mathrm{~h}$. The maturation medium consisted of TCM 199 (M 2154) with $1 \mathrm{mM}$ L-glutamine, $1 \mathrm{mM}$ sodium pyruvate (P 3662), $0.1 \mathrm{mM}$ 2-mercaptoethanol (M 7522), $50 \mathrm{ng} / \mathrm{ml}$ epidermal growth factor (E 4127), $50 \mu \mathrm{g} / \mathrm{ml}$ gentamicin and $0.1 \%(\mathrm{w} / \mathrm{v})$ BSA (A 3311). During the first $24 \mathrm{~h}$ of IVM, the medium was supplemented with $10 \mathrm{IU} / \mathrm{ml}$ PMSG and $5 \mathrm{IU} / \mathrm{ml} \mathrm{hCG}$ (Suigonan Vet, Intervet Scandinavia, Skovlunde, Denmark) and $5 \mu \mathrm{l} / \mathrm{ml}$ ITS (recombinant human insulin, human transferrin, and sodium selenite, I 3146).

\section{Sperm preparation}

The semen was prepared either by SLC or by standard centrifugation (control). The SLC was performed according to [8]. In brief, the extended semen was further diluted in BTS to approximately $1 \times 10^{8}$ sperm cells $/ \mathrm{ml}$; $4.5 \mathrm{ml}$ were carefully layered on top of $4 \mathrm{ml}$ Androcoll-P in a $15 \mathrm{ml}$ tube. The tube was centrifuged at $300 \times g$ for $20 \mathrm{~min}$ at room temperature and the supernatant was removed. The sperm pellet was transferred to pre-gassed IVF medium (see below). An additional SLC-sperm preparation was done in parallel to provide a sample for computer assisted sperm motility analysis. The sperm pellet from the latter was resuspended in BTS containing BSA (5 $\mathrm{mg} / \mathrm{ml}$ ) to prevent the spermatozoa aggregating or sticking to the glass surfaces during motility assessment [8]. For the control group, sperm was prepared by two centrifugations in $4 \mathrm{ml}$ of non-capacitating medium at $300 \times g$ for $5 \mathrm{~min}$ at room temperature. Sperm noncapacitating medium consisted of $113 \mathrm{mM} \mathrm{NaCl}$ (S 5886), $5 \mathrm{mM} \mathrm{KCl}$ (P 5405), $6 \mathrm{mM} \mathrm{D-glucose} \mathrm{(G} \mathrm{6152),} 1 \mathrm{mM}$ $\mathrm{KH}_{2} \mathrm{PO}_{4}$ (P 5655), $1 \mathrm{mM} \quad \mathrm{MgSO}_{4} \cdot 7 \mathrm{H}_{2} \mathrm{O}$ (M 1880), $22 \mathrm{mM}$ lactic acid (L 7900), $5 \mu \mathrm{g} / \mathrm{ml}$ phenol red (P 5530) and $50 \mu \mathrm{g} / \mathrm{ml}$ gentamicin. The resulting pellets from both preparation methods were diluted in $4 \mathrm{ml}$ of IVF medium and kept at $38.5^{\circ} \mathrm{C}$ in $5 \% \mathrm{CO}_{2}$ in air and maximum humidity for $15 \mathrm{~min}$ while sperm concentrations were determined using a NucleoCounter SP-100 (ChemoMetec, Allerød, Denmark). To reach the desired sperm concentrations and oocyte:sperm ratios, the sperm dilutions were further diluted in IVF medium.

\section{Computer assisted sperm motility analysis}

Sperm motility was analyzed using a Mika Cell Motility Analyser (MTM Medical Technologies Montreux, Switzerland) after incubating the samples at $38^{\circ} \mathrm{C}$ for $30 \mathrm{~min}$; only the total and progressively motile spermatozoa were recorded for this experiment. Motility was evaluated in BTS containing BSA $(5 \mathrm{mg} / \mathrm{ml})$. An aliquot $(5 \mu \mathrm{L})$ of the sample in a pre-warmed Makler counting chamber (Sefi Medical Instruments, Haifa, Israel) was analyzed using the following software settings: 32 frames per sequence, a minimum of 15 frames per object, minimum area for objects 25 pix, 
velocity limit for immobile objects $=10 \mu \mathrm{m} / \mathrm{s}$, velocity limit for locally motile objects $=25 \mu \mathrm{m} / \mathrm{s}$ [16]. Motile spermatozoa were classified as linear (spermatozoa deviating less than $10 \%$ from a straight line), circular (spermatozoa moving in a circle with a radius less than $25 \mu \mathrm{m}$ ), and non-linear (spermatozoa falling into neither of the first two categories). At least 200 spermatozoa were analyzed for each sample.

\section{In vitro fertilization}

After in vitro maturation, the oocytes were washed twice in IVF medium and randomly assigned to the different sperm treatments. Spermatozoa were prepared as indicated above and diluted in IVF medium to compare the following treatments: control (standard centrifugation) at 1:50 and 1:100 oocyte:sperm ratios or SLCtreated at 1:50; $1: 100$ or 1:300 (corresponding to $4 \times$ $10^{3} ; 8 \times 10^{3}$ or $24 \times 10^{3}$ cells $/ \mathrm{ml}$, respectively). IVF medium consisted of $90 \mathrm{mM} \mathrm{NaCl}, 12 \mathrm{mM} \mathrm{KCl}$, $0.5 \mathrm{mM} \mathrm{NaH} \mathrm{PO}_{4}$ (S 5011), $25 \mathrm{mM} \mathrm{NaHCO}, 1 \mathrm{mM}$ $\mathrm{MgSO}_{4} \cdot 7 \mathrm{H}_{2} \mathrm{O}, 2 \mathrm{mM}$ sodium pyruvate, $8 \mathrm{mM} \mathrm{CaCl}{ }_{2}$. $2 \mathrm{H}_{2} \mathrm{O}$ (C 7902), $6 \mathrm{mM}$ lactic acid, $1 \mathrm{mM}$ caffeine (C 0750), $5 \mu \mathrm{g} / \mathrm{ml}$ phenol red, $50 \mu \mathrm{g} / \mathrm{ml}$ gentamicin, and $0.6 \%(\mathrm{w} / \mathrm{v})$ BSA. Since the number of available oocytes was different between batches, the groups of oocytes per treatment ranged from 40 to 49 depending on the experimental day. To keep the IVF conditions constant using the total number of oocytes available, approximately $12 \mu \mathrm{l}$ of IVF medium per oocyte was used (500$612 \mu \mathrm{l}$ IVF medium depending on the replicate). Therefore the number of oocytes per group and the final IVF volume were equal in each replicate. The oocyte:sperm ratio and the final sperm concentration were also constant between replicates to allow comparisons. Nine independent experiments were performed (1519 oocytes). Since three to five treatments could be tested per batch, the treatments were rotated throughout the experiments (always with control present, resulting in 6-8 replicates per group; Table 1). The gametes were incubated together at $38.5^{\circ} \mathrm{C}$ under $5 \% \mathrm{CO}_{2}$ in air and maximum humidity for $24 \mathrm{~h}$. Day 0 was defined as the day of fertilization.

\section{In vitro culture and blastocyst assessment}

The oocytes (presumptive zygotes) were transferred to $750 \mu \mathrm{l}$ of NCSU-23 [17] supplemented with $10 \mathrm{mM}$ HEPES (H-6147), $50 \mu \mathrm{g} / \mathrm{ml}$ insulin (I-6634) and $25 \mu \mathrm{g} / \mathrm{ml}$ gentamicin. Any remaining cumulus cells and excess spermatozoa were removed by vortexing for $1 \mathrm{~min}$. Some oocytes were not recovered during this process, presumably due to adhesion to plastic and/or ruptured zona pellucida; therefore, data are expressed over the total number of retrieved and subsequently cultured presumptive zygotes. After vortexing, presumptive zygotes were transferred to $500 \mu \mathrm{l}$ of in vitro culture medium (PZM-3) [18]. The numbers of early cleaved zygotes at $24 \mathrm{~h}$ after fertilization and total cleavage rates (48 h post insemination, hpi) were assessed in HEPES-NCSU-23. At this point, non-cleaved oocytes were removed and stained. Fertilization ratios were calculated retrospectively and included the percentage of non-cleaved oocytes with $\geq 2$ pronuclei-like structures (thus, including polyspermic oocytes) that were arrested and were not able to cleave, plus the embryos found at $48 \mathrm{hpi}$. The embryos were transferred to fresh PZM-3 in groups of 35-45 and covered with $300 \mu \mathrm{l}$ of mineral oil (M 8410). Culture was maintained up to day 7 at $38.5^{\circ} \mathrm{C}$ in a mixture of $5 \% \mathrm{CO}_{2}, 5 \%$

Table 1 Effect of sperm treated with colloids at different oocyte:sperm ratios on in vitro embryo development (mean \pm SEM)

\begin{tabular}{|c|c|c|c|c|c|c|}
\hline \multirow[t]{2}{*}{$\begin{array}{l}\text { Treatment Ratio } \\
\text { oocyte: spermatozoa }\end{array}$} & \multirow[t]{2}{*}{$\mathrm{n}$} & $\begin{array}{l}\text { Spermatozoa } \\
\text { bound to the ZP }\end{array}$ & \multirow{2}{*}{$\begin{array}{l}\text { Polyspermic } \\
\text { oocytes (\%) } \\
\text { (over non-cleaved } \\
\text { oocytes) }\end{array}$} & \multirow{2}{*}{$\begin{array}{l}\text { Fertilization rate } \\
\text { (\%) } \\
\text { Over No. } \\
\text { Presumptive zygotes }\end{array}$} & \multirow{2}{*}{$\begin{array}{l}\text { Cleavage rate } \\
(48 \mathrm{hpi} \% \\
\text { No. embryos/No. } \\
\text { presumptive zygotes }\end{array}$} & \multirow{2}{*}{$\begin{array}{l}\begin{array}{l}\text { Blastocyst rate } \\
\text { (day 7)\% }\end{array} \\
\text { No. blastocysts/No. } \\
\text { presumptive zygotes }\end{array}$} \\
\hline & & $\begin{array}{l}\text { No. spermatozoa } \\
\text { (over non-cleaved } \\
\text { oocytes) }\end{array}$ & & & & \\
\hline \multirow[t]{2}{*}{ Control 1:50 } & 6 & $9.4 \pm 6.5^{a}$ & $8.2 \pm 3.0^{a}$ & $59.3 \pm 4.4^{a}$ & $55.7 \pm 4.0^{a}$ & $12.5 \pm 2.0^{a}$ \\
\hline & & (344/128) & $(11 / 126)$ & $(175 / 292)$ & $(164 / 292)$ & $(37 / 292)$ \\
\hline \multirow[t]{2}{*}{ Control 1:100 } & 8 & $5.1 \pm 0.6^{a}$ & $27.6 \pm 6.2^{b}$ & $67.0 \pm 5.1^{a b}$ & $55.1 \pm 4.9^{a}$ & $17.7 \pm 3.7^{a}$ \\
\hline & & $(758 / 145)$ & $(37 / 141)$ & $(215 / 317)$ & $(174 / 317)$ & $(55 / 317)$ \\
\hline \multirow[t]{2}{*}{ SLC 1:50 } & 6 & $2.9 \pm 0.6^{\mathrm{a}}$ & $15.3 \pm 5.4^{\mathrm{a}}$ & $62.9 \pm 5.5^{\mathrm{a}}$ & $56.0 \pm 4.2^{\mathrm{a}}$ & $16.0 \pm 4.1^{\mathrm{a}}$ \\
\hline & & $(328 / 136)$ & $(16 / 134)$ & $(183 / 304)$ & $(167 / 304)$ & $(47 / 304)$ \\
\hline \multirow[t]{2}{*}{ SLC 1:100 } & 8 & $6.7 \pm 1.2^{\mathrm{a}}$ & $36.4 \pm 7.9^{b}$ & $73.5 \pm 3.4^{\mathrm{ab}}$ & $56.2 \pm 3.2^{a}$ & $15.8 \pm 2.2^{\mathrm{a}}$ \\
\hline & & $(944 / 135)$ & $(51 / 132)$ & $(244 / 315)$ & $(176 / 315)$ & $(49 / 315)$ \\
\hline \multirow[t]{2}{*}{ SLC 1:300 } & 7 & $20.5 \pm 2.1^{b}$ & $66.5 \pm 6.7^{c}$ & $78.4 \pm 2.8^{b}$ & $31.0 \pm 4.3^{b}$ & $5.2 \pm 1.4^{b}$ \\
\hline & & $(4118 / 194)$ & (133/194) & $(224 / 291)$ & $(91 / 291)$ & $(15 / 291)$ \\
\hline
\end{tabular}


$\mathrm{O}_{2}$ and $90 \% \mathrm{~N}_{2}$ and maximum humidity. On day 7 after fertilization, blastocyst rates were evaluated and the blastocysts were graded according to the International Embryo Transfer Society classification (scored one to four where one is the best grade) [19].

\section{Nuclear staining}

Non-cleaved oocytes and blastocysts were fixed in $2 \%$ paraformaldehyde overnight at $4^{\circ} \mathrm{C}$ and stained with $4.45 \mu \mathrm{M}$ Hoechst 33342 (B 2261) for $20 \mathrm{~min}$ at room temperature before being mounted in Vectashield (Vector laboratories, Inc. Burlinggame, CA, USA) on glass slides and assessed using an epifluoresent microscope (Leitz GmbH Dialux 20, Wetzlar, Germany). The non-cleaved oocytes were assessed for polyspermy (more than two pronuclei-like objects per oocyte) and number of accessory spermatozoa bound to the zona pellucida (ZP). The number of nuclei in the blastocysts was counted.

\section{Statistical analysis}

Statistical analyses were performed using Statistica (Statsoft, Inc. 2001. STATISTICA, data analysis software system, version 6; www.statsoft.com). The number of spermatozoa bound to the $\mathrm{ZP}$, the percentage of polyspermic oocytes, fertilization, cleavage and blastocyst rates were analyzed using main-effects ANOVA where sperm treatment (control or SLC) and oocyte: spermatozoa ratios (1:50, 1:100 or 1:300) were considered as independent variables. Before the analysis, normal distribution of data and residuals were tested using Shapiro-Wilk's test. Homogeneity of variances was evaluated using Levene's test. Dependent variables expressed as percentages were arcsine-transformed and the number of spermatozoa attached to the ZP was logtransformed to satisfy parametric assumptions. When significant differences were found, comparison between treatments was made using the post hoc Tukey test. The blastocyst nuclei number and quality scoring on day 7 were analyzed using Kruskal-Wallis ANOVA. In addition, total and progressive sperm motility in SLC or uncentrifuged samples were evaluated using a $\mathrm{t}$-test for dependent samples. Results are presented as mean \pm S.E. $\mathrm{M}$, with $\mathrm{P}<0.05$ being considered significant.

\section{Results}

Both the total motility and progressive motility were significantly higher in SLC-sperm samples than in uncentrifuged semen $(\mathrm{P}<0.05)$ (Table 2). The number of spermatozoa bound to the ZP was not affected by sperm treatment, but there was an effect of the oocyte:sperm ratio $\left(\mathrm{F}_{2,31}=14 ; \mathrm{P}<0.001\right)$. A significantly higher number of spermatozoa were bound in the 1:300 than 1:50 and 1:100 groups (Table 1). Sperm treatment did not affect the percentage of polyspermic oocytes, but polyspermy was influenced by sperm concentration $\left(\mathrm{F}_{2,31}=16.9 ; \mathrm{P}<0.001\right)$. Increasing oocyte:sperm ratios resulted in increased polyspermy and fertilization rates $(\mathrm{P}<0.05)$ (Table 1$)$. Early cleavage rate was similar in all groups, ranging from $6.0 \pm$ 2.0 to $7.1 \pm 1.4 \%(\mathrm{P}>0.05)$. The total cleavage rate was not affected by sperm treatment, but was affected by sperm concentration $\left(\mathrm{F}_{2,31}=12.7 ; \mathrm{P}<0.001\right)$, being significantly lower in the SLC 1:300 group (Table 1). Blastocyst yield was not affected by the sperm preparation method but was affected by sperm:oocyte ratios $\left(\mathrm{F}_{2,31}=7.4 ; \mathrm{P}<0.003\right)$, with the SLC 1:300 group having a significantly lower blastocyst rate (Table 1 ). Blastocyst quality grade and number of blastomeres did not differ (Table 3).

\section{Discussion}

This study has allowed us to evaluate the fertilizating ability of boar sperm selected by SLC using in vitro matured oocytes. The SLC treatment did not negatively affect the ability of boar spermatozoa to undergo fertilization and the embryos generated were able to develop to the blastocyst stage in the same proportion as the embryos produced in the control group.

SLC through Androcoll-P selects good quality boar spermatozoa $[8,9]$. However, previous attempts in our laboratory using IVF with these spermatozoa resulted in polyspermic zygotes, precluding embryo development (Sjunnesson YCB, González R and Morrell JM, unpublished observations). It is likely that the increased motility in the SLC samples, and probably improvements in other variables of sperm quality such as morphology and viability [8,9], may have accounted for the increased polyspermy caused by the use of Androcoll-P (Sjunnesson YCB, González R and Morrell JM, unpublished observations). This is in agreement with previous studies by others using colloid-prepared spermatozoa for IVF in the boar. Sperm treated by centrifugation through discontinuous Percoll gradient displayed higher motility and sperm binding to the $\mathrm{ZP}$, and penetration rates were also enhanced, which resulted in an increase in polyspermy [20,21]. Since colloid-selected spermatozoa seemed to have an increased ability to fertilize $[20,21]$ or at least improved sperm quality $[8,9]$, the ability of SLC-prepared spermatozoa to fertilize in vitro matured oocytes with subsequent development to the blastocyst stage was assessed in the

Table 2 Sperm motility

\begin{tabular}{lccc}
\hline Treatment & $\mathbf{n}$ & Total motility\% (Cl) & Progressive motility\% (Cl) \\
\hline Uncentrifuged & 9 & $71 \pm 7^{\mathrm{a}}$ & $69 \pm 6^{\mathrm{a}}$ \\
& & $(54$ to 87$)$ & $(54$ to 83$)$ \\
SLC & 9 & $91 \pm 2^{\mathrm{b}}$ & $79 \pm 5^{\mathrm{b}}$ \\
& & $(87$ to 94$)$ & (69 to 89) \\
\hline
\end{tabular}

Mean \pm SEM and $95 \%$ confidence interval $(\mathrm{Cl})$.

Different letters denote significant differences between treatments $(P<0.05)$.

The number of replicates where each treatment was analyzed is indicated $(n)$. 
Table 3 Blastocyst nuclei counts and blastocyst quality (mean \pm SEM)

\begin{tabular}{ccccc}
\hline Treatment Ratio oocyte: spermatozoa & $\mathbf{n}$ & Blastocyst cell number & $\mathbf{n}$ & Blastocyst quality grade \\
\hline Control 1:50 & 32 & $42.7 \pm 3.3$ & 35 & $2.07 \pm 0.11$ \\
Control 1:100 & 44 & $39.2 \pm 2.4$ & 50 & $1.94 \pm 0.10$ \\
SLC 1:50 & 47 & $41.4 \pm 2.2$ & 45 & $1.79 \pm 0.08$ \\
SLC 1:100 & 36 & $41.7 \pm 2.3$ & 39 & $2.19 \pm 0.13$ \\
SLC 1:300 & 10 & $41.3 \pm 4.2$ & 13 & $2.00 \pm 0.24$ \\
\hline
\end{tabular}

There were no significant differences between groups. The number of blastocysts analyzed is indicated (n). Blastocyst quality grade range was 1 to 4 , where grade 1 is the best grade.

present study with lower oocyte:sperm ratios than previously used. No negative effects of SLC-treated spermatozoa on in vitro parameters such as cleavage, blastocyst rate or blastocyst quality compared to controls were observed, in agreement with the results reported using SLCtreated bull spermatozoa [6]. However, the establishment of pregnancy and litter size after embryo transfer of these blastocysts, as well as the in vivo fertilization ability of SLC-selected spermatozoa, has yet to be ascertained.

Polyspermy, caused by simultaneous penetration by several spermatozoa [22,23], occurs in vivo and in vitro in the pig [24], and could be a cause of embryonic loss [22]. In the present study, few embryos developed when oocyte:sperm ratios over 1:100 were used in the SLCgroup. Surprisingly, although the 1:300 ratio was not included in the control, the commonly used ratios in the control treatment for this particular sperm donor (between $1: 1250$ to $1: 3000$ ), resulted in a cleavage rate of around 50\% and blastocyst rate above 15\% (Sjunnesson YCB, González R, Morrell JM, unpublished observations). The lower cleavage and blastocyst rates consistently observed in the SLC 1:300 group were most probably due to the significantly higher polyspermy seen in this group. In agreement with our results, spermatozoa treated with Percoll had faster oocyte penetration and higher blastocyst yield, and a reduced incubation time of $2 \mathrm{~h}$ of gamete interaction was found to be sufficient, since longer incubations caused increased polyspermic rates [20]. In the latter study, an oocyte: spermatozoa ratio of approximately 1:715-1:830 (25 × $10^{4}$ sperm cells $/ \mathrm{ml}$ ) was used for up to $6 \mathrm{~h}$ of gamete co-incubation, in comparison to the longer incubation time of gametes $(24 \mathrm{~h})$ in the present study, which may lead to a higher incidence of polyspermy when sperm concentration was increased in the SLC-group. The percentage of acrosome-reacted spermatozoa was greater after treatment with Percoll [20]. It is unknown if the acrosome reaction and capacitation status of boar spermatozoa are changed in SLC-treated sperm, although these parameters are currently under investigation. Furthermore, it would be interesting to determine these parameters using shorter incubation times. This would allow evaluation of the fertilizing ability of SLC- treated sperm versus control samples and determination of the optimal time of gamete incubation to increase the efficiency of the IVF system using spermatozoa prepared by SLC.

Our results demonstrate that the function of boar SLC-selected sperm is not hampered in IVF. However, the advantages of SLC in IVF for boars which already have high sperm quality may be difficult to evaluate because of the problem of polyspermy. Nonetheless, SLC could be very useful in genetically valuable males with reduced semen quality or in non-commercial breeds that present lower male selection for breeding purposes and, therefore, a wider range in semen quality.

In comparison to other colloid methods, such as density gradient centrifugation, the use of SLC present advantages for boar semen due to its simplicity of preparation, species-specific formulations and the possibility of processing large volume of ejaculates [8]. In addition, SLC could be useful for selecting good quality spermatozoa after freezing $[25,26]$ and sex sorting where numbers of viable spermatozoa can be low $[27,28]$. SLC could also be a useful tool in porcine intracytoplasmic sperm injection [29] where the aspect of polyspermy is irrelevant. Moreover, SLC has shown promise in removing or significantly reducing bacteria and viruses in pig semen $[5,30]$ and, as such, may have an important role to play in biosecurity in the future and may help to reduce the use of antibiotics in semen extenders.

\section{Conclusion}

In summary, SLC can select boar sperm without affecting their functionality, as demonstrated in the IVF system. Boar semen selected by means of SLC support embryo development in vitro at the same rates as their untreated counterparts. Since SLC-samples seemed to have an increased fertility potential, boar-related adjustments to the IVF conditions and probably shortening the interaction period between gametes will be needed to avoid an increased incidence of polyspermy and improve the efficiency of the IVF system. These results could be important for the future use of SLC-prepared sperm in artificial insemination trials. 


\section{Abbreviations}

ANOVA: Analysis of variance; BSA: Bovine serum albumin; BTS: Beltsville thawing solution; hCG: Human chorionic gonatotropin; HEPES: 4-(2Hydroxyethyl)-1-piperazineethanesulfonic acid; Hpi: Hours post insemination; ITS: Insulin, transferrin, and sodium selenite; IVF: In vitro fertilization; IVM: In vitro maturation; NCSU: North Carolina State University; PSP-I: PSP-II, Porcine seminal plasma proteins I and II; PMSG: Pregnant mare's serum gonatotropin; PZM: Porcine zygote medium; SEM: Standard error of the mean; SLC: Single layer centrifugation; ZP: Zona pellucida.

\section{Competing interests}

The authors declare there are no competing interests.

\section{Authors' contributions}

YCBS discussed the proposal, approved the final plan, prepared the oocytes for IVF and culture of embryos as well as analyses of oocytes and blastocysts and did the major writing of the article. JMM discussed the proposal, approved the final plan, performed the SLC and motility analysis, assisted with preparing the oocytes for IVF, assisted with writing the article and has approved the final draft. RG discussed the proposal, approved the final plan, prepared the oocytes for IVF and culture of embryos as well as analyses of oocytes and blastocysts, performed all statistical analyses and assisted with writing the article and has approved the final draft. All authors read and approved the final manuscript.

\section{Acknowledgements}

We thank the animal husbandry staff of the Division for their excellent care of the boars. Ickholmen slaughterhouse is acknowledged for providing the ovaries and Monica Nilsson for her help collecting the ovaries. Funded by Formas (221 2007-374 and 221-2010-549) and the Swedish Farmers' Foundation (V7050239), Stockholm, Sweden.

\section{Received: 29 October 2012 Accepted: 1 March 2013}

Published: 5 March 2013

\section{References}

1. Suarez S: Interactions of spermatozoa with the female reproductive tract: inspiration for assisted reproduction. Reprod Fertil Dev 2007, 19:103-110.

2. Morrell J, Rodríguez-Martínez H: Biomimetic techniques for improving sperm quality in animal breeding: a review. The Open Andrology J 2009, 1:1-9.

3. Henkel RR, Schill WB: Sperm preparation for ART. Reprod Biol Endocrinol 2003, 1:108.

4. Morrell J, Rodríquez-Martínez H: Practical applications of sperm selection techniques as a tool for improving reproductive efficiency. Vet Med International 2011, 2011. doi:10.4061/2011/894767. Article ID 894767.

5. Morrell J, Wallgren M: Removal of bacteria from boar ejaculates by single layer centrifugation can reduce the use of antibiotics in semen extenders. Anim Reprod Sci 2011, 123:64-69.

6. Thys M, Vandaele L, Morrell J, Mestach J, van Soom A, Hoogewijs M, Rodriguez-Martinez $\mathrm{H}$ : In vitro fertilizing capacity of frozen-thawed bull spermatozoa selected by single-layer (glycidoxypropyltrimethoxysilane) silane-coated silica colloidal centrifugation. Reprod Domest Anim 2009, 44:390-394

7. Morrell J, Mari G, Kútvölgyi G, Meurling S, Mislei B, lacono E, RodriguezMartinez $\mathrm{H}$ : Pregnancies following artificial insemination with spermatozoa from problem stallion ejaculates processed by single layercentrifugation with Androcoll-E. Reprod Domest Anim 2011, 46:642-645.

8. Morrell J, Saravia F, van Wienen M, Wallgren M, Rodriguez-Martinez $\mathrm{H}$ : Selection of boar spermatozoa using centrifugation on a glycidoxypropyltrimethoxysilane-coated silica colloid. J Reprod Dev 2009, 55:547-552.

9. van Wienen M, Johannisson A, Wallgren M, Parlevliet J, Morrell J: Single layer centrifugation with Androcoll-P can be scaled-up to process larger volumes of boar semen. ISRN Vet Sci 2011, 2011. doi:10.5402/2011/548385 Article ID 548385 .

10. Kruse R, Dutta P, Morrell J: Colloid centrifugation removes seminal plasma and cholesterol from boar spermatozoa. Reprod Fertil Dev 2011, 23:858-865.

11. Morrell J, Wallgren M: Androcoll ${ }^{\mathrm{T}}$-P-Large selects boar spermatozoa with good membrane integrity from the sperm-rich fraction of the ejaculate. Anim Reprod 2010, 7:16-20.
12. Caballero I, Vázquez JM, Gil MA, Calvete JJ, Roca J, Sanz L, Parrilla I, García EM, Rodríguez-Martínez H, Martínez E: Does seminal plasma PSP-I/PSP-II spermadhesin modulate the ability of boar spermatozoa to penetrate homologous oocytes in vitro? J Androl 2004, 25:1004-1012.

13. Centurion F, Vazquez JM, Calvete JJ, Roca J, Sanz L, Parrilla I, Garcia EM, Martinez EA: Influence of porcine spermadhesins on the susceptibility of boar spermatozoa to high dilution. Biol Reprod 2003, 69:640-646.

14. García EM, Vázquez JM, Calvete JJ, Sanz L, Caballero I, Parrilla I, Gil MA, Roca $J$, Martínez EA: Dissecting the protective effect of the seminal plasma spermadhesin PSP-I/PSP-II on boar sperm functionality. J Androl 2006, 27:434-443.

15. Simonsson A: Nutrient recommendations for pigs [in Swedish]. Uppsala, Sweden: Swedish University of Agricultural Sciences, SLU Info. Rapporter Husdjur; 1994:75

16. Eriksson B, Vazquez J, Martinez E, Roca J, Lucas X, Rodriguez-Martinez H: Effects of holding time during cooling and type of packaging on plasma membrane integrity, motility and in vitro oocyte penetration ability of frozen-thawed boar spermatozoa. Theriogenology 2001, 55:1593-1605.

17. Petters R, Wells K: Culture of pig embryos. J Reprod Fertil Suppl 1993, 48:61-73.

18. Yoshioka K, Suzuki C, Tanaka A, Anas I, Iwamura S: Birth of piglets derived from porcine zygotes cultured in a chemically defined medium. Biol Reprod 2002, 66:112-119.

19. Gordon I: Laboratory production of cattle embryos, Biotechnology in Agriculture Series No. 27. Secondth edition. Dublin, Ireland: CABI Publishing; 2003.

20. Matás C, Coy P, Romar R, Marco M, Gadea J, Ruiz S: Effect of sperm preparation method on in vitro fertilization in pigs. Reproduction 2003, 125:133-141.

21. Coy P, Gadea J, Rath D, Hunter R: Differing sperm ability to penetrate the oocyte in vivo and in vitro as revealed using colloidal preparations. Theriogenology 2009, 72:1171-1179.

22. Hunter R: Oviduct function in pigs, with particular reference to the pathological condition of polyspermy. Mol Reprod Dev 1991, 29:385-391.

23. Wang W, Day B, Wu G: How does polyspermy happen in mammalian oocytes? Microsc Res Tech 2003, 61:335-341.

24. Gil M, Cuello C, Parrilla I, Vazquez J, Roca J, Martinez E: Advances in swine in vitro embryo production technologies. Reprod Domest Anim 2010, 45(Suppl 2):40-48.

25. Macías García B, González Fernández L, Morrell JM, Ortega Ferrusola C, Tapia JA, Rodriguez Martínez H, Peña FJ: Single-layer centrifugation through colloid positively modifies the sperm subpopulation structure of frozenthawed stallion spermatozoa. Reprod Domest Anim 2009, 44:523-526.

26. Macías García B, Morrell JM, Ortega-Ferrusola C, González-Fernández L, Tapia $J A$, Rodríguez-Martínez H, Peña FJ: Centrifugation on a single layer of colloid selects improved quality spermatozoa from frozen-thawed stallion semen. Anim Reprod Sci 2009, 114:193-202.

27. Roca J, Rodríguez-Martínez H, Vázquez J, Bolarín A, Hernández M, Saravia F, Wallgren M, Martínez E: Strategies to improve the fertility of frozenthawed boar semen for artificial insemination. Soc Reprod Fertil Suppl 2006, 62:261-275.

28. Vázquez J, Parrilla I, Roca J, Gil M, Cuello C, Vázquez J, Martínez E: Sexsorting sperm by flow cytometry in pigs: issues and perspectives. Theriogenology 2009, 71:80-88.

29. Nakai M, Kashiwazaski N, Takizawa A, Hayashi Y, Nakatsukasa E, Fuchimoto D, Noguchi J, Kaneko H, Shino M, Kikuchi K: Viable piglets generated from porcine oocytes matured in vitro and fertilized by intracytoplasmic sperm head injection. Biol Reprod 2003, 68:1003-1008.

30. Blomqvist $\mathrm{G}$, Persson $\mathrm{M}$, Wallgren $\mathrm{M}$, Wallgren $\mathrm{P}$, Morrell J: Removal of virus from boar semen spiked with porcine circovirus type 2. Anim Reprod Sci 2011, 126:108-114

\section{doi:10.1186/1751-0147-55-20}

Cite this article as: Sjunnesson et al:: Single layer centrifugation-selected boar spermatozoa are capable of fertilization in vitro. Acta Veterinaria Scandinavica 2013 55:20. 